\title{
Effect of Arterial Hypertension on Postoperative Mortality and Morbidity after Off-pump CABG Surgery
}

\author{
Asraful Hoque, Shahriar Moinuddin \\ Department of Cardiac Surgery, NICVD, Dhaka,
}

\begin{abstract}
Key words: Coronary artery disease, Hypertension, Coronary artery bypass.
\end{abstract}

\begin{abstract}
:
Background: Arterial hypertension is one of the leading modifiable risk factor in coronary artery disease patients who underwent coronary artery bypass grafting (CABG) with the major impact on clinical outcome in these patients. This study was done to evaluate the effect of arterial hypertension on postoperative mortality and morbidity after off-pump CABG.

Methods: 200 patients with mean age of $52 \pm 6$ years, (182 male/18 female) undergoing off pump $C A B G$ were divided equally into two groups, 100 patients with hypertension (Group A) and 100 patients without hypertension (Group B). Postoperative mortality and morbidities (Wound infection, AMI, TIA, Stroke) up to 6 months were recorded in the 2 groups.

Results: In comparison with the normotensive patients, hypertensive patients had a higher mortality rate (Group A $10 \%$ and Group B $2 \%, p$ value-<0.05) and increased frequency of myocardial infarction (Group A $12 \%$ and Group B 3\%, p value - <0.05). There was also increased rate of infection in hypertensive patients (Group A $13 \%$ and Group B 4\%, p value - <0.05). We found that hypertensive patients developed post-operative cerebrovascular complications like TIA (Group A $8 \%$ and Group B 1\%, p value - <0.05) and stroke (Group A $11 \%$ and Group B 2\%, p value - <0.05) more frequently than normotensive patients. Post-operative ventilator support and duration of hospital stay were almost similar in both groups.
\end{abstract}

Conclusions: Among CABG patients, those with a history of hypertension have an increased frequency of post-operative complications and increased mortality.

(Cardiovasc. j. 2017; 10(1): 13-16)

\section{Introduction}

Coronary heart disease (CAD) is the most common form of heart disease and the single most important cause of premature death in Europe, the Baltic States, Russia, North and South America, Australia and New Zealand. ${ }^{1}$ The prevalence of IHD in Bangladesh was first reported in 1976, which was $0.33 \%$ and in 1985 it was $1.4 \% .^{2,3}$ But recent data shows CAD prevalence between $1.85 \%$ and $3.4 \%$ in rural areas and $19.6 \%$ among urban working professionals. ${ }^{4-7}$ These value shows a rising prevalence of CAD in Bangladesh. A study done by rural Bangladesh demonstrated a dramatic increase in CVD from 1986 to 2006. Mortality rate from CVD increased by 30 -fold (from 16 to 483 deaths per 100,000) among males and 47 -fold (from 7 to 330 deaths per 100,000) in females. ${ }^{8}$

Arterial hypertension is one of the leading modifiable risk factor in coronary artery disease patients who underwent CABG surgery.Hypertension and its complications account for an estimated 9.4 million deaths every year. ${ }^{9}$ Previous reports have suggested that hypertension has some deleterious effect after myocardial revascularizations. Candidates for coronary bypass surgery having a history of hypertension have increased 2 year mortality after the bypass procedure. ${ }^{10}$

In Bangladesh, $20 \%$ of adult and $40-65 \%$ of elderly people suffer from hypertension and the factors that play role in the pathophysiology of hypertension are metabolic syndrome, obesity, high salt intake and less physical activety. ${ }^{11}$

In another study, Bangladesh Non-communicable Disease (NCD) Risk Factor Survey 2010 from November 2009 to April 2010 shows prevalence of hypertension is $17.9 \%$ in general, $18.5 \%$ in men and $17.3 \%$ in womenamong the population aged 25 years and above. ${ }^{12}$ Such a high prevalence of hypertension

Address for Correspondence: Dr. Asraful Hoque, Department of Cardiac Surgery, National Institute of Cardiovascular Diseases, Dhaka, Bangladesh. e-mail-dr_asraf_sium@yahoo.com 
may contribute to the high prevalence of $\mathrm{CAD}$ in Bangladesh,

To find out the influence of hypertension on postoperative mortality and morbidity after off-pump CABG surgery, this study was conducted from January 2014 to December 2015, in the Department of Cardiac surgery, National Institute of Cardiovascular Diseases.

\section{Methods:}

Two hundred patients undergoing off pump CABG were divided equally into two groups, 100 patients with hypertension (Group A) and 100 patients without hypertension (Group B), on the basis of the definition of hypertension of Society of thoracic surgeons, National adult cardiac surgery database. ${ }^{13}$

Other major risk factors for ischemic heart diseases (Hyperlipidemia, smoking, diabetes mellitus and family history of coronary artery disease) were matched between the groups. All patients with clinical and angiographic evidence of coronary artery disease were included in the study regardless of age and gender.

Patients with combined CABG and valvular or congenital cardiac procedures, systemic disease such as end stage renal disease, hepatic failure, respiratory failure, Previous history of cardiac surgery, emergency $\mathrm{CABG}$, redo $\mathrm{CABG}$ were excluded from the study.

Detailed history of each patient under study was recorded, with special attention to the age, sex, risk factors for $\mathrm{CAD}$ and co-morbidities for CABG. Important and relevant findings on thorough physical examinations and investigations were collected preoperatively and data during operative period, in the intensive care unit, in the ward and follow up to 6 month period after operation were recorded. Postoperative mortality and morbidities (Wound infection, AMI, TIA, Stroke) up to 6 months were recorded and compared in the 2 groups.

\section{Results:}

In this study, we describe Effect of arterial hypertension on postoperative mortality and morbidity after off-pump CABG surgery

Table I show that thirteen percent of Group-A (patients having hypertension) patients developed wound infection after coronary bypass surgery, while only 4 percent of the Group-B developed the same infection.

Table II shows that eight patients from the Group A developed TIA stroke, but only one patients of the Group B patient had the same problem.

Table III shows that eleven patients from the Group A developed stroke, but only two patients of the Group $B$ patient had the same problem.

Table IV shows that in patients having hypertension (Group A), 12 (12.0\%) developed postoperative MI whereas 4 (3.0\%) of patients having no hypertension (Group B) developed postoperative MI.

Table $\mathrm{V}$ shows that among the Group A mortality rate is $10 \%$ while it is only $2 \%$ in group 2 .

Regarding intensive care unit and hospital stay, no significant differences were observed between the two groups.

Table-I

Wound infection as postoperative complication in the study population $(n=200)$.

\begin{tabular}{lcccc}
\hline Group & \multicolumn{2}{c}{ Wound infection } & Total patients & p-value \\
\cline { 2 - 3 } & Yes & No & & \\
\hline Group A & $13(13.0 \%)$ & $87(87.0 \%)$ & 100 & $<0.05$ \\
Group B & $04(4.0 \%)$ & $96(96.0 \%)$ & 100 & \\
\hline
\end{tabular}

Table-II

Transient ischaemic attack as postoperative complication in the study population ( $n=200)$.

\begin{tabular}{|c|c|c|c|c|}
\hline \multirow[t]{2}{*}{$\overline{\text { Group }}$} & \multicolumn{2}{|c|}{ Stroke } & \multirow[t]{2}{*}{ Total patients } & \multirow[t]{2}{*}{$\overline{p \text {-value }}$} \\
\hline & Yes & No & & \\
\hline Group A & $8(8.0 \%)$ & $92(92.0 \%)$ & 100 & $<0.05$ \\
\hline Group B & $1(1.0 \%)$ & 99 (99.0\%) & 100 & \\
\hline
\end{tabular}


Table-III

Stroke as postoperative complication in the study population $(n=200)$.

\begin{tabular}{lcccc}
\hline Group & \multicolumn{2}{c}{ Stroke } & Total patients & p-value \\
\cline { 2 - 4 } & Yes & No & & \\
\hline Group A & $11(06.7 \%)$ & $89(89.0 \%)$ & 100 & $<0.05$ \\
Group B & $02(00.0 \%)$ & $98(98.0 \%)$ & 100 & \\
\hline
\end{tabular}

Table IV

Myocardial Infarction as postoperative complication in the study population $(n=200)$.

\begin{tabular}{lcccc}
\hline Group & \multicolumn{2}{c}{ Complications } & Total patients & p-value \\
\cline { 2 - 4 } & Yes & No & & \\
\hline Group A & $12(12.0 \%)$ & $88(88.0 \%)$ & 100 & $<0.05$ \\
Group B & $3(3.0 \%)$ & $97(8697.7 \%)$ & 100 & \\
\hline
\end{tabular}

Table-V

Mortality rate as postoperative complication in the study population $(n=200)$.

\begin{tabular}{lcccc}
\hline Group & \multicolumn{2}{c}{ Mortality } & Total patients & p-value \\
\cline { 2 - 3 } & Yes & No & & \\
\hline Group A & $10(10.0 \%)$ & $90(90.0 \%)$ & 100 & $<0.05$ \\
Group B & $02(02.0 \%)$ & $98(98.0 \%)$ & 100 & \\
\hline
\end{tabular}

\section{Discussion:}

Coronary artery bypass surgery (CABG) is a well established surgical procedure in Bangladesh. Patients with co-morbidity have greater risk of having post-operative complications. The present study did not find any significant association between demographic variables (age and sex) and postoperative complications

In this study it is shown that complications after CABG in hypertensive patients far outweighed that among normotensive. The influence of risk factors (like smoking, diabetes mellitus, hyperlipidemia, family history of CAD) on number of postoperative complications as compared between cases and controls did not show any significant relationship.

As postoperative complications were compared between the groups, it was revealed that $13 \%$ of the cases of Group-A developed wound infection after CABG surgery, while only $4 \%$ of the Group-B developed the same infection.

Some $8 \%$ of the Group-A and 1\% of the Group-B, had Post-operative TIA and about 11\% patients from the Group A developed stroke, but only 2\% patients of the Group B had the same problem. Gupta et al. identified stroke as a major complication of' CABG and reported rates range from $0.4 \%$ to $13.8 \%$. Recognized correlates were prior stroke, hypertension, increasing age and diabetes mellitus. ${ }^{14}$

Roach GW et al. carried out a prospective investigation of adverse cerebral outcomes after elective CABG surgery. ${ }^{15}$ Post-operative cerebrovascular complications and the subsequent development of stroke were more frequent among hypertensive patients. This is an expected finding since the risk of stroke has been shown to increase in hypertensive patients with other manifestations of ischemic heart disease. ${ }^{16}$

We have seen that hypertensive patients have more chance to develop MI than normotensive patient. A history of hypertension has been reported to increase the risk of reinfarction. ${ }^{17,18}$

In our study within first 6 months after the operation, thehypertensive patients tended to have a higher mortalitythan the non-hypertensive patients.In the Coronary Artery Surgery Study(CASS), which included patients over 65 years of age, itwas shown that hypertensive individuals 
had a 5 -yearmortality of $21 \%$ compared with $15 \%$ for non-hypertensivepatients $(\mathrm{P}<0.005) .{ }^{19}$

In the present study ventilation time and total ICU stay shows no major difference at all. Total postoperative stay was higher in hypertensive patients.

\section{Conclusion:}

Among CABG patients, those with a history of hypertension have an increased frequency of postoperative complications and an increased mortality. Rational measures should be undertaken to contain the post-operative complications of CABG in hypertensive patients to minimal tolerable level. It is recommended to design strategies to improve outcome of CABG operation.

\section{Conflict of Interest - None.}

\section{References:}

1. Bhatia JY, Pandey K, Rodrigues C, Mehta A, Joshi VR. Postoperative Wound Infection in Patients Undergoing Coronary Artery Bypass Graft Surgery: A Prospective Study with Evaluation of Risk Factors. Indian J Med Microbiol 2003; 21 (4): 264-251.

2. Malik A. Congenital and acquired heart disease- A study of 762 persons. Bangladesh Med Res Coun Bull 1976; 2: $115-119$.

3. Amanullah M. Intravenous thrombolitics in acute myocardial infraction (Editorial). Bangladesh Heart Journal 1994; 9:1-4.

4. Sayeed MA, Mahtab H, Sayeed S. Prevalence and risk factors of coronary heart disease in a rural population of Bangladesh. Ibrahim Med Coll J 2010; 4:37-43.

5. Zaman MM, Ahmed J, Choudhury SR. Prevalence of ischemic heart disease in a rural population of Bangladesh. Indian Heart Journal 2007; 59: 239-241.

6. Ahsan S, Haque KMHS, Salman M. Detection of ischaemic heart disease with risk factors in different categories of employees of University Grants Commission. University Heart Journal 2009; 5: 20-23.

7. Saquib N, Saquib J, Ahmed T. Cardiovascular diseases and type 2 diabetes in Bangladesh: a systematic review and meta-analysis of studies between 1995 and 2010 . BMC Public Health 2012; 12: 434.
8. Ahsan K Z, Alam N, Kim SP. Epidemiological transition in rural Bangladesh, 1986-2006. Glob Health Action 2009:2.

9. Lim SS, Vos T, Flaxman AD, Danaei G, Shibuya K, Adair-Rohani $\mathrm{H}$, et al. A comparative risk assessment of burden of disease and injury attributable to 67 risk factors and risk factor clusters in 21 regions, 19902010: a systematic analysis for the Global Burden of Disease Study 2010. Lancet 2012; 380(9859):2224-2260.

10. Herlitz J, Brandup-Wognsen G, Haglid M, Hartford M, Emanuelsson H, et al. Mortality and morbidity during a period of two years after coronary artery bypass surgery in patients with and without a history of hypertension. J Hypertens 1996; 14:309-314.

11. Islam AKMM, Majumder AAS. Hypertension in Bangladesh: A review. Indian Heart Journal 2012; 6403: 319-323.

12. World Health Organization. Non-Communicable Disease Risk Factor Survey Bangladesh 2010. [cited 2013 Jul 3]. Available from: http://www.ban. searo. who.int/LinkFiles/Publication_ NCD_Risk_ Factor_ Survey_Report.pdf.

13. Society of thoracic surgeons (STS). STS adult cardiac database: definitions of terms. Available at: http:// www.sts.org/database/corefullspecs235.pdf.accessed May 10,2002.

14. Gupta V, Grover V. Risk assessment and outcome after CABG. Annals of Cardiac anesthesia 2002; 5:156-158.

15. Roach GW, Kanchuger M, Mangano CM, Newman M, Nussmeier N, Wolman R, et al. Adverse cerebral outcomes after coronary bypass surgery. $N$ Engl $J$ Med 1996 Dec 19;335(25):1857-1863.

16. Kannel WB, Dawber TR, Sorlie P, Wolf PA. Components of blood pressure and risk of atherothrombotic brain infarction: The Framingham study. Stroke 1976, 7:327-333.

17. Wilhelmsson C, Vedin JA, Elmfeldt D, Tibblin G, Wilhelmsen L. Hypertension and myocardial infarction. J Chronic Dis 1978, 31:157-164.

18. Ulvenstam G, Aberg A, Pennet K, Vedin A, Wedel H, Wilhelmsen L, et al. Recurrent myocardial Infarction. II. Possibilities of prediction. Eur Heart $J$ 1985, 6:303-311.

19. Gersh BJ, Kronmal RA, Schaff HV, Frye RL, Ryan TJ, Myers WO, et al. Long-term (5 year) results of coronary bypass surgery in patients 65 years old or older: a report from the Coronary Surgery Study. Circulation 1983, 68: II-190-III-199. 